\title{
Performance Evaluation of Minimum Quantity Lubrication (MQL) using CBN Tool during Hard Turning of AISI 4340 and its Comparison with Dry and Wet Turning
}

\author{
D.V. Lohar and C.R. Nanavaty
}

\begin{abstract}
In order to increase the flexibility and ability to manufacture complex geometry, hard turning was introduced where the necessity of grinding operation can be eliminated. In hard turning rough machining, final grinding can be eliminated and raw material is supplied in the final heat treated condition. Hard turning can seriously be regarded as an alternative for grinding operations under certain circumstances. Generally hard turning requires large quantities of coolants and lubricants. The cost of associated with lubricants increases the total cost of production considerably. Conventional cutting fluid application fails to penetrate the chip-tool interface and thus cannot remove heat effectively. Considering cost and the stricter environmental laws are enforced, alternatives has been sought to minimize the use of cutting fluid in machining operations. Some of these are dry machining and machining with Minimum Quantity Lubrication $(M Q L)$. Present work deals with the comparative performance of CBN tool in machining AISI4340 steel in conventional dry and wet turning with Minimum Quantity Lubrication by varying speed and feed, depth of cut. The experiments were conducted using standard $L_{18}\left(2^{1} \times 3^{7}\right)$ mixed orthogonal array. Statistical analysis was performed using MINITAB software for ANOVA analysis, mean effects and interaction plots.
\end{abstract}

Keywords--- Hard Turning, AISI 4340 Steel, CBN Tool, Minimum Quantity Lubrication $(M Q L)$

\section{INTRODUCTION}

$\mathrm{T}$ HE conventional method of manufacturing a component has the following sequences namely soft machining, heat treatment, rough turning and fine grinding. In order to increase the flexibility and ability to manufacture complex geometry, hard turning was introduced where the necessity of grinding operation can be eliminated. In hard turning rough machining, final grinding can be eliminated and raw material is supplied in the final heat treated condition. Hard turning can seriously

D.V. Lohar, Senior Lecturer, Department of Mechanical Engineering, Shri.H.H.J.B. Polytechnic, Chandwad, Dist: Nashik (MS), India. E-mail: drdinesh2012@rediffmail.com

C.R. Nanavaty, Principal, Shri.H.H.J.B. Polytechnic, Chandwad, Dist: Nashik (MS), India. E-mail: shekharnanavaty@ rediffmail.com be regarded as an alternative for grinding Operations under certain circumstances. Generally hard turning requires large quantities of coolants and lubricants. The cost of procurement, storage and disposal of coolants and lubricants increases the total cost of production considerably. Conventional cutting fluid application fails to penetrate the chip-tool interface and thus cannot remove heat effectively.

Considering the high cost associated with the use of cutting fluids and projected costs when the stricter environmental laws are enforced, some alternatives has been sought to minimize or even avoid the use of cutting fluid in machining operations. Some of these alternatives are dry machining and machining with minimal fluid application. Dry machining is now of great interest and actually, they meet with success in the field of environmentally friendly manufacturing. However, they are sometimes less effective when higher machining efficiently, better surface finish quality and serve cutting conditions are required. In these situations, semi dry operations utilizing very small amounts of cutting lubricants are expected to become powerful tool, in fact, they already play a significant role in a number of practical applications. Minimal fluid application refers to the use of cutting fluids of only a minute amount typically of flow rate of 50 to $500 \mathrm{ml} /$ hour. The concept of minimal fluid application sometimes referred to as near dry lubrication or micro lubrication.

According to the regulations of Occupational Safety and Health Administration (OSHA), the permissible exposure level (PEL) for mist within a plant is $5 \mathrm{mg} / \mathrm{m}^{3}$ and is likely to be reduced to $0.5 \mathrm{mg} / \mathrm{m}^{3}$. By introducing the cutting fluid precisely at the cutting zone, better cutting performance can be achieved which will result in better surface finish, low cutting force and reduction of tool wear. In minimal fluid application, extremely small quantities of specially prepared cutting fluids are required and it almost resembles dry turning. In the case of minimal application, heat transfer is predominantly in the evaporative mode, which is more efficient than the convective heat transfer prevalent in conventional wet turning. The review of the literature suggests that minimal fluid application provides several benefits in machining. Present work deals with the comparative performance of CBN tool in machining hardened alloy steel in conventional dry turning and wet turning with minimum fluid application

DOI: 10.9756/BIJIEMS.4392 


\section{REVIEW OF LITERATURE}

The positive effect of the use of fluids in metal cutting was first reported in 1894 by F.Taylor, who noticed that by applying large amounts of water in cutting area, the cutting speed could be increased up to $33 \%$ without reducing tool life. Since then, cutting fluid effect has been studied resulting in an extensive range of products covering most work piece material and operations. However the costs associated mainly with fluid handling, recycling and disposal are leading to alternatives such as new tool material and coating which allows dry machining and application of small quantities of fluid as mist spray. N.R. Dhar and others [1] reported that the cutting performance of AISI 1060 by minimal quantity lubrication machining by vegetable oil is better than that of dry machining because minimal quantity lubrication provides the benefits mainly by reducing the cutting temperature, which improves the chip tool interaction and maintains sharpness of the cutting edges. The cutting forces are reduced by about $5 \%$ to $15 \%$.The minimal lubrication reduced the cutting zone temperature and favorable changes in the chip-tool and worktool interactions, which helped in reducing friction, built up edges formation, thermal distortion and wear of the cutting tool. P.S. Sreejith, B.K.A. Ngoi[2] explained dry machining as a option for machining without use of cutting fluids. B.Ramamoorthy $[3,6]$ reported the overall performance of the cutting tools during minimal cutting fluid application was found to be superior to that compared to dry turning and conventional wet turning on the basis of parameters such as cutting force, temperature and surface finish. The influence of operating parameters in minimal fluid application was evaluated and it was observed that cutting performance mainly depends on fluid application parameters such as pressure and delivery rate. Wuyi Chen[4]Cutting forces and surface finish generated using $\mathrm{CBN}$ tools have been evaluated when cutting steel hardened to 45 55 HRC and radial thrust force (Fy) became the largest among the three cutting force components and was most sensitive to the changes of cutting edge chamfer, tool nose radius and flank wear.E.O. Ezugwua, R.B. Da Silvaa, J. Bonneya, A .R. Machadob [5] conducted experiments using high pressure coolant supply for machining of Ti-6Al-4V alloy using CBN tool. R.F.Aliva,A.L.Abrao[7] the performance of three types of cutting fluids (two emulsions and one synthetic fluid) were compared to dry cutting when continuous turning hardened AISI 4340 steel (49 HRC) using mixed alumina inserts and parameters were evaluated are tool life, surface finish, tool wear mechanisms and chips form.Machado and Wall bank[8] reported that the application of cutting fluid as spray mist at rates of 200-300 $\mathrm{ml} / \mathrm{hr}$ when turning medium carbon steel at low cutting speeds and high feed rates resulted in lower cutting and feed forces and superior surface finish compared to overhead flooding. Machining cost is another relevant aspect to be considered. According to Kress, the costs associated with the use of cutting fluids represent approximately $17.5 \%$ of the finished work piece cost against $4 \%$ spent with tooling. M. Sokovic $\hat{A}$, K. Mijanovica[9] discussed ecological aspects of cutting fluid which are very important considering regulations of Occupational Safety and Health Administration (OSHA). Nikhil Ranjan Dhar, Sumaiya Islama, Mohammad
Kamruzzaman [10] has studied the effect of Minimum Quantity Lubrication (MQL) on Tool Wear Surface Roughness and Dimensional Deviation in Turning AISI-4340 Steel. Ronan Autret,Steven Y. Liang, George W. Woodruff [11] conducted experiments on finish hard turning using Minimum Quantity Lubrication for the turning of hardened bearing-grade steel materials, The results indicate that the use of minimum quantity lubrication leads to reduced surface roughness, delayed tool flank wear, and lower cutting temperature. Wisley F. Sales, Álisson R. Machado, John Bonney Emmanuel O. Ezugwu [12] has evaluated use of Cutting Fluids Using Scratch Tests and Turning Process. Tugrul Özel, Tsu-Kong Hsu, Erol Zeren[13]studied the effects of cutting edge geometry, workpiece hardness, feed rate and cutting speed on surface roughness and forces in finish turning of hardened AISI h13 steel. B. Fnides, M. A. Yallese, H. Aouici [14] conducted experiments for hard turning of hot work steel AISI H11: and evaluatedfor cutting pressures, resulting force and temperature. M.Y. Noordin, V.C. Venkatesh, S. Sharif, S. Elting, A. Abdullah [15] in this paper,application of response surface methodology is used for describing the performance of coated carbide tools when turning AISI 1045 steel.Present work deals with the performance evaluation of CBN tool in machining AISI4340 steel using minimal fluid application with parameters speed and feed, depth of cut. Catalogue of WIDIA-Kennametal[16] is used for selection of $\mathrm{CBN}$ insert for the hard turning process. Catalogue of Kistler dynamometer, K-type thermocouple, Mitutoyo talysurf [17]are necessary for set up of hard turning for experimentation.

\section{EXPERIMENTAL DETAILS}

\section{A. Work Piece}

The work piece material is hardened alloy steel 4340 with diameter $60 \mathrm{~mm}$ and length $300 \mathrm{~mm}$. The size is selected from the review of other similar work and machine specifications available for experimental work.

\section{B. Cutting Tool}

CBN insert TNMA160404 Grade PB250 of Kennametal Widia is selected along with tool holder PTGNR/L2525M16

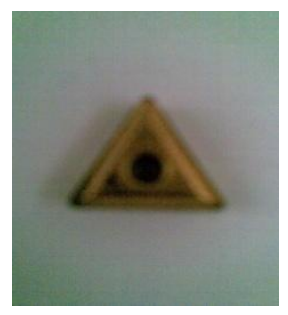

Fig.1 TNMA Insert

\section{Machine}

A high speed precision CNC Lathe (Jobber XL Make) having 7.5 HP electric motor and $5000 \mathrm{rpm}$ was used for experimental work.

\section{Cutting Fluid Application}

The quantity of cutting fluid used in this method is very low (5 to $20 \mathrm{ml} / \mathrm{min}$ ), the cutting oil is available commercially in formulated form. The lubricator used in pneumatic system 
is adjusted to supply a jet of cutting fluid at $10 \mathrm{ml} / \mathrm{min}$ and 20 $\mathrm{ml} / \mathrm{min}$ at 6 bar pressure. The supply is directed at tool-work piece contact zone.

\section{E. Process Parameters and their Levels}

Based on the literature review the process parameters were chosen which are listed in following table. The parameters which directly affecting the hard turning process are cutting speed, feed, depth of cut and cutting fluid application.

Table 1: Parameters with Levels

\begin{tabular}{|l|l|}
\hline A. Parameter & Level \\
\hline Feed rate (mm/rev) & $0.05,0.075,0.10$ \\
\hline Cutting speed (m/min) & $40,80,120$ \\
\hline Depth Of Cut (mm) & $0.5,1.0$ \\
\hline Cutting fluid condition & Dry, Wet, MQL \\
\hline
\end{tabular}

\section{F. Response Variables}

It is seen from the published literature that the machinability of hard turning process is evaluated in terms of cutting forces, surface roughness, cutting temperature, tool wear and tool life. Considering the practical constrains, cutting forces, surface roughness and cutting temperature were selected as a response variables to assess the machining performance in hard turning of alloy steel 4340.The performance can be evaluated and compared by measurement of surface finish using Mitutoyo surface tester, cutting temperature by K-type Thermocouple model-T505-8804 Hanna instruments and cutting forces using Kistler 3 axis Dynamometer

\section{$G$ Design of Experiment}

During the experimentation, a large number of experiments have to carry out as the number of machining parameters increases. Taguchi's design of experiment involves proper selection of an orthogonal array to accommodate variables (input factors) and their interactions.

The experiments were conducted using standard $\mathrm{L}_{18} 2^{1}$ $x 3^{7}$ ) Taguchi mixed orthogonal array. According to the array eighteen experiments were conducted as per selected orthogonal array. The depth of cut is two level factors while other factors have three levels hence mixed orthogonal array is selected. The experiments are conducted in random order with three replicates to reduce the effect of noise factors.

\section{H. Experimental Procedure}

It is represented with the help of flow chart.
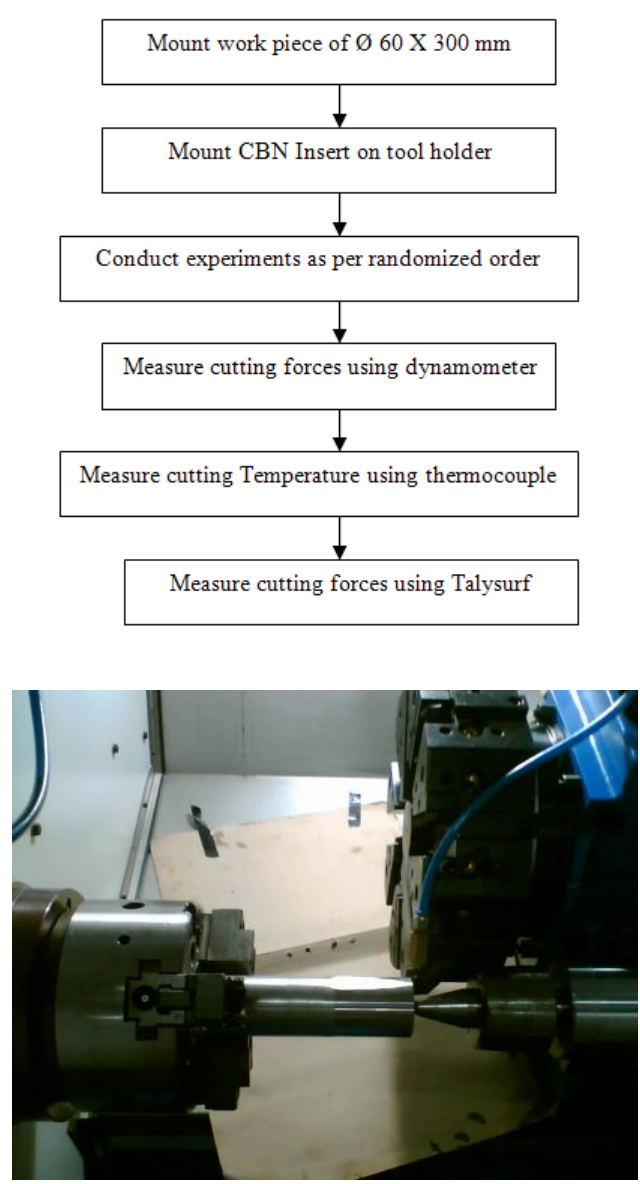

Fig.3: Experimental Setup

\section{ANALYSIS}

Hard turning operation involves various input variables that include cutting speed, feed rate, and depth of cut and application of coolant. These variables have direct as well as indirect effect on the performance of hard turning process. The effect of coolant quantity can be expressed in terms of the performance variables such as cutting forces, surface finish and cutting temperature is observed and analyzed.

Based on the experimental work, the results were analyzed and it consists of the assessment of cutting force, cutting temperature and surface roughness components hard turning of alloy steel 4340. The analysis was performed in order to determine the effect of coolant quantity on the cutting force, cutting temperature and surface roughness component and Statistical analysis was performed using MINITAB software. The analyzed results were presented using ANOVA analysis and mean effects plots.

\section{A. Analysis of Cutting Forces}

Fig. 3 shows almost all machining parameters show linear dependence on the variation in cutting force produced during hard turning. It is observed from main effect plot generated using MINITAB that cutting fluid environment has higher contribution to the variability of cutting forces over the other experimental factors. The main effect plot shows the range of cutting forces varies from $390 \mathrm{~N}$ to $250 \mathrm{~N}$ for the dry cutting 
to MQL cutting environment. There is considerable reduction in the cutting forces during MQL condition.

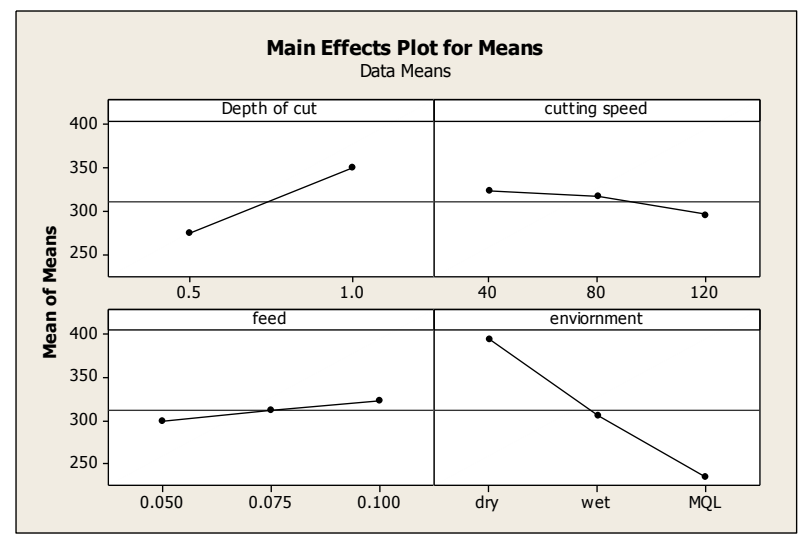

Fig. 3: Main Effect Plots for Cutting Forces

Analysis of Variance (ANOVA) is carried out using MINITAB software to investigate difference in average performance of factors under test. ANOVA breaks total variation in to accountable sources and helps to determine the most significant factors in the experiments.

DF- Degree of freedom, Adj.SS- Adjusted sum of squares, Adj.MS- Adjusted mean square, F- Factor for total deviation

Table 2: ANOVA Analysis of Cutting Forces

\begin{tabular}{|l|l|l|l|l|}
\hline Source & DF & Adj.SS & Adj MS & F \\
\hline DOC & 1 & 25916 & 25916 & $16.29 *$ \\
\hline Cutting speed & 2 & 2469 & 1235 & 0.78 \\
\hline Feed & 2 & 1523 & 762 & 0.48 \\
\hline Environment & 2 & 77174 & 38587 & $24.26 *$ \\
\hline Error & 10 & 15905 & 1590 & \\
\hline Total & 17 & *Significant \\
\hline
\end{tabular}

From general linear model of ANOVA, F-value for cutting environment is $24.26(\mathrm{P}<0.001)$ hence it is most significant parameter and next significant parameter is depth of cut which has $\mathrm{F}$ value is $16.29(\mathrm{P}=0.002)$, In MQL method the cutting fluid is supplied at higher pressure 6 bar and high velocity, due to which better penetration of cutting fluid to the underside of the chip. This creates its passage to reduce the friction between tool and chip. The reduction of friction reduces the cutting forces, such condition is not possible in wet turning because there is no such fragmentation takes place as velocity and pressure in wet turning is less than MQL.

\section{$B$ Analysis of Cutting Temperature}

Fig.4 shows main effect plot for cutting temperature. The effect of various parameters shows linear relationship.

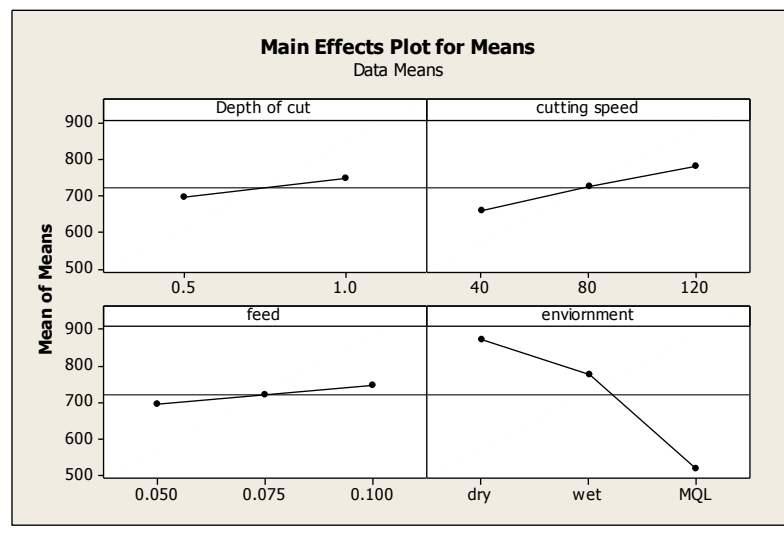

Fig.4: Main Effect Plots for Cutting Temperatures

The temperature is one of the most important factor which affects tool life and tool performance. It is observed that the cutting temperature during MQL condition is lower than dry and wet turning.

From general linear model of ANOVA, F-value for cutting environment is $64.11(\mathrm{P}<0.001)$ hence it is most significant parameter. In MQL the cutting fluid particles can reach up to tool chip interface in the form of small drops. During wet turning, the heat is extracted only by convective heat transfer, but MQL facilitates both convective and evaporative heat transfer leads to lowering of cutting temperature.

Table 3: ANOVA Analysis of Cutting Temperatures

\begin{tabular}{|l|l|l|l|l|}
\hline Source & DF & Adj.SS & Adj MS & F \\
\hline DOC & 1 & 10952 & 10952 & 3.50 \\
\hline Cutting speed & 2 & 44219 & 22110 & 7.07 \\
\hline Feed & 2 & 7871 & 3936 & 1.26 \\
\hline Environment & 2 & 400975 & 200487 & $64.11 *$ \\
\hline Error & 10 & 31273 & 3127 & \\
\hline Total & 17 & *Significant \\
\hline
\end{tabular}

\section{Analysis of Surface Finish}

Almost all machining parameters show linear dependence on the variation in Surface finish produced during hard turning. The surface finish obtained during MQL is better than dry and wet turning. During MQL condition, fluid is correctly placed at the contact of the tool and the work piece. Hence the chips are easily removed and give better surface finish.

From the ANOVA table, the most significant parameter is environments. The value of $\mathrm{F}$ is $216.42(\mathrm{P}<0.001)$ while the next significant parameter is feed. The surface finish depends upon the feed rate of the tool with respect to work piece and the supply of cutting fluid. As depth of cut increases the poor surface finish occurs. 


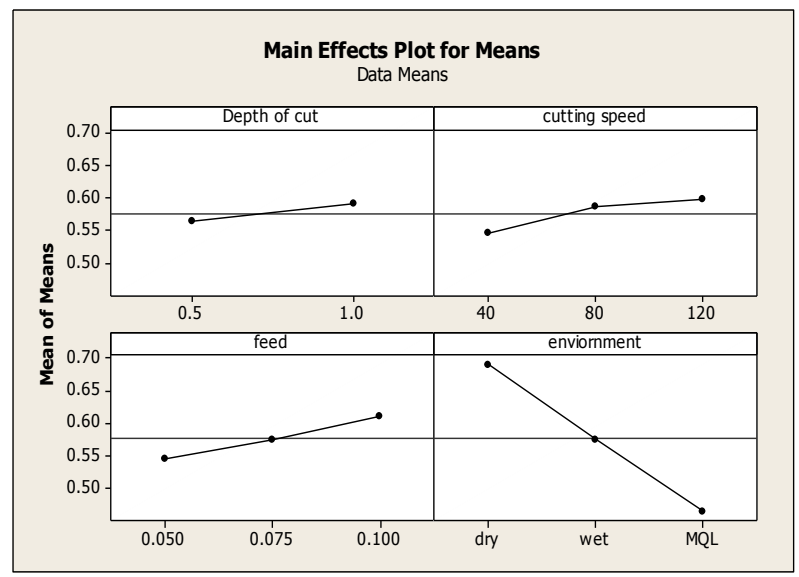

Fig. 5: Main Effect Plots for Surface Finish

Table 4: ANOVA Analysis of Surface Finish

\begin{tabular}{|l|l|l|l|l|}
\hline Source & DF & Adj.SS & Adj MS & F \\
\hline DOC & 1 & 0.003528 & 0.003528 & 9.98 \\
\hline $\begin{array}{l}\text { Cutting } \\
\text { speed }\end{array}$ & 2 & 0.009105 & 0.004553 & 12.88 \\
\hline Feed & 2 & 0.012985 & 0.006493 & 18.37 \\
\hline $\begin{array}{l}\text { Environme } \\
\text { nt }\end{array}$ & 2 & 0.153008 & 0.076504 & $\begin{array}{l}216.4 \\
*\end{array}$ \\
\hline Error & 10 & 0.003535 & 0.000354 & \\
\hline Total & 17 & *Significant \\
\hline
\end{tabular}

\section{CONCLUSION}

From the experimental investigations in hard turning of hardened alloy steel AISI 4340 based on Taguchi's method and the analysis of response variables, the following conclusions are drawn -

1) It is observed that the cutting force in hard turning of hardened AISI 4340 is less as compared to dry and wet turning. There is $40 \%$ decrease in cutting forces during MQL. While for wet flood condition it was about $26 \%$ more than MQL and 19\% less than dry condition.

2) It is observed that the cutting temperature in hard turning of hardened AISI 4340 is less as compared to dry and wet turning. It gives $36 \%$ decrease in cutting temperature. The MQL shows lower range of temperature which helps to improve tool life.

3)It is observed that the surface finish in hard turning of hardened AISI 4340 is better as compared to dry and wet turning. There is $30 \%$ improvement in surface finish using MQL.

\section{REFERENCES}

[1] M.M.A. Khan and N.R. Dhar, "Performance evaluation of minimum quantity lubrication by vegetable oil in terms of cutting force, cutting zone temperature, tool wear, job dimension and surface finish in turning AISI-1060 steel" Journal of Zhejiang University Science, Pp. 17901799, 2006-07.

[2] P.S. Sreejith and B.K.A. Ngoi" Dry machining Machining of the future" Journal of Materials Processing Technology, Pp. 287-291, 2000.
[3] CH R. Vikram Kumar and B. Ramamoorthy" Performance of coated tools during hard turning under minimum fluid application" Journal of Materials Processing Technology, Volume xxx, Pp. 32-37, 2006.

[4] Wuyi Chen, "Cutting forces and surface finish when machining medium hardness steel using CBN tools", International Journal of Machine Tools \& Manufacture Volume 40, Pp. 455-466, 2000.

[5] E.O. Ezugwua, R.B. Da Silvaa, J. Bonneya and A.R. Machadob "Evaluation of the performance of CBN tools when turning Ti-6Al-4V alloy with high pressure coolant supplies", International Journal of Machine Tools \& Manufacture, Volume 45, Pp. 1009-1014, 2005.

[6] A.S. Varadarajan, P.K. Philip and B. Ramamoorthy, "Investigations on hard turning with minimal cutting fluid application (HTMF) and its comparison with dry and wet turning," International Journal of Machine Tools \& Manufacture ,Volume 42, Pp.193-200, 2002.

[7] R.F. Aliva and A.L. Abrao, "Effects of the cutting fluids on the machining of hardened AISI 4340" Steel,Journal of material processing technology Volume 119, Pp. 21-26, 2001.

[8] A.R. Machado and J. Wallbank b, "The effect of extremely low lubricant volumes in machining," Wear, Volume 210, Pp. 76-82, 1997.

[9] M. SokovicÂ and K. Mijanovica, "Ecological aspects of the cutting fluids and its influence on quantifiable parameters of the cutting processes", Journal of Materials Processing Technology, Volume 109, Pp. 181-189, 2001.

[10] Nikhil Ranjan Dhar and Sumaiya Islama, Mohammad Kamruzzaman "Effect of Minimum Quantity Lubrication (MQL) on Tool Wear Surface Roughness and Dimensional Deviation in Turning AISI-4340 Steel", G.U. J. Sci., Volume 20, No. 2, Pp. 23-32, 2007.

[11] Ronan Autret, Steven Y. Liang and George W. Woodruff "Minimum Quantity Lubrication in Finish Hard Turning", HNICEM, Pp. 1-9,2003.

[12] Wisley F. Sales, Álisson R. Machado and John Bonney Emmanuel O. Ezugwu,"Evaluation of Cutting Fluids Using Scratch Tests and Turning Process" J. of the Braz. Soc. of Mech. Sci. \& Eng., Volume XXIX, No. 4, Pp. 372-378, October-December 2007.

[13] Tugrul Özel, Tsu-Kong Hsu and Erol Zeren "Effects of cutting edge geometry, workpiece hardness, feed rate and cutting speed on surface roughness and forces in finish turning of hardened AISI h13 steel "Department of Industrial and Systems Engineering Rutgers, The State University of New Jersey, 08854 USA.

[14] B. Fnides, M.A. Yallese and H. Aouici "Hard turning of hot work steel AISI H11: Evaluation of cutting pressures, resulting force and temperature" Mechanics and Structures Laboratory (LMS), Department of Mechanical Engineering, University, Guelma, Volume 24, Algeria, May 08th 1945.

[15] M.Y. Noordin, V.C. Venkatesh, S. Sharif, S. Elting and A. Abdullah "Application of response surface methodology in describing the performance of coated carbide tools when turning AISI 1045 steel" Journal of Materials Processing Technology, Volume 145, Pp. 46-58, 2004.

[16] Catalogue of WIDIA-Kennametal

[17] Catalogue of Kistler dynamometer, K-type thermocouple, Mitutoyo talysurf

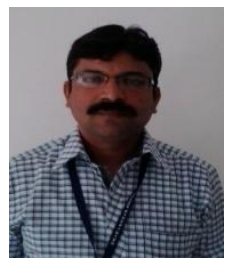

D.V. Lohar was born in Maharashtra, India, on July 25 , 1975. He received the B. E. Production from S.G.G.S. College of Engineering, Nanded (Dr.B.A.M.University, Aurangabad Maharashtra, India in 1996 and received Gold Medal as a Topper. M.E in Production Engineering from Shivaji University, Kolhapur, Maharashtra, India in 2010. He is having total experience more than 15 years in Industry and Teaching. He published more than 10 papers in National, International conferences. His research interests are manufacturing and supply chain management, six sigma, Japanese management techniques 